\title{
PRIMING PRINCIPLE AND RAPID SEQUENCE INTUBATION WITH NON-DEPOLARISING MUSCLE RELAXANT VECURONIUM BROMIDE
}

\author{
M. Srinivasa Rao ${ }^{1}$, T. V. V. S. V. Prasad ${ }^{2}$, Kumudha ${ }^{3}$
}

${ }_{1}^{1}$ Associate Professor, Department of Anaesthesia, SV Medical College, Tirupathi, Andhra Pradesh.

${ }^{2}$ Assistant Professor, Department of Anaesthesia, RIMS, Vizayanagaram, Andhra Pradesh.

3Postgraduate Student, Department of Anaesthesia, SV Medical College, Tirupathi, Andhra Pradesh.

\section{ABSTRACT}

\section{BACKGROUND}

Succinylcholine cannot be used for rapid sequence intubation (RSI) in several situations due to associated side effects. Vecuronium bromide has faster onset of time among non-depolarising muscle relaxants and can offer safe alternative for RSI when the priming principle used.

The aim of the study is to evaluate the intubating conditions and time required for rapid, smooth tracheal intubation using the "principle of priming" with non-depolarising muscle relaxant vecuronium bromide.

The objective of the study was taken up with the primary objective of evaluating the different priming doses of vecuronium bromide at the time of intubation and the secondary objective of evaluating the intubation conditions.

\section{MATERIALS AND METHODS}

A study consisting of 60 patients of different age and of both sexes were divided into 3 groups to assess the intubation time and the intubation conditions using "priming principle" with vecuronium bromide. Group I consists of 20 patients who received a bolus dose of $0.1 \mathrm{mg} / \mathrm{kg}$ vecuronium, the mean intubating time was 149 seconds and in $70 \%$ of cases. In Group II, 20 patients received a priming dose of $0.015 \mathrm{mg} / \mathrm{kg}$, intubating dose of $0.6 \mathrm{mg} / \mathrm{kg}$ with 5 minutes interval. Adequate intubating conditions were achieved in 96 seconds in $80 \%$ of cases. Group III consists of 20 patients who received a priming dose of $0.02 \mathrm{mg} / \mathrm{kg}$ and intubating dose of 0.08 $\mathrm{mg} / \mathrm{kg}$. Adequate intubating conditions were achieved in 63 seconds in all patients. Time of intubation was assessed using train-offour (TOF) stimuli and intubation conditions were compared as per Lemon et al, 1986.

Settings and Design- This randomised, prospective, double-blind study was conducted in patients for abdominal, head and neck surgeries under general anaesthesia in the Department of Anaesthesia; SVRR Govt. General Hospital, Tirupati, AP.

\section{RESULTS}

The onset time of intubation was $149 \pm 13$ in Group I, $96 \pm 12$ in Group II and $63 \pm 7.1$ in Group III. Intubating conditions were clinically acceptable in all three groups.

\section{CONCLUSION}

This study concluded that vecuronium bromide can be used for rapid tracheal intubation (RSI) utilising "priming principle."

\section{KEYWORDS}

Priming, Rapid Sequence Intubation, Vecuronium Bromide, Non-Depolarising Neuromuscular Blocking Agents.

HOW TO CITE THIS ARTICLE: Rao MS, Prasad TVVSV, Kumudha. Priming principle and rapid sequence intubation with nondepolarising muscle relaxant vecuronium bromide. J. Evolution Med. Dent. Sci. 2018;7(11):1308-1312, DOI: $10.14260 /$ jemds/2018/298

\section{BACKGROUND}

Ever since the introduction of various muscle relaxants, the choice is still uncertain for intubation. Efforts by several workers all over the world are in progress to make intubation a rapid and safe procedure for the patient. ${ }^{1}$

Anaesthesiologists have long considered succinylcholine as the muscle relaxant of choice for rapid sequence intubation. Several recent developments suggest that our thinking regarding the rapid sequence procedure needs a revision.

'Financial or Other Competing Interest': None.

Submission 03-02-2018, Peer Review 27-02-2018,

Acceptance 05-03-2018, Published 12-03-2018.

Corresponding Author:

Dr. M. Srinivasa Rao,

Associate Professor,

Department of Anaesthesia

SV Medical College/SVRR G Hospital,

Tirupathi, Andhra Pradesh.

E-mail: manduri60@gmail.com

DOI: $10.14260 /$ jemds $/ 2018 / 298$

\section{(c) (i) $\$$}

Succinylcholine is currently the drug of choice to facilitate rapid intubation of trachea during anaesthesia, but frequently is associated with some undesirable side effects such as muscle fasciculations, post-operative muscle pain, hyperkalaemia, increased intraocular pressure, increased intragastric pressure and malignant hyperthermia. In instances when succinylcholine has been contraindicated or undesirable, use of large doses of non-depolarising neuromuscular blocking drugs have been suggested (Mehta MP et al.).

When non-depolarising muscle relaxants are used, the time required for smooth intubation is 2 - 3 minutes. In order to reduce this long interval between the administration of relaxant to optimal intubation conditions, several anaesthesiologists have recommended administration of subparalysing dose of the non-depolariser a few minutes before giving a large calculated dose for smooth tracheal intubation (Gergis SD; Hutton P; Foldes FF, Schwartz S, Mehta MP).

Suxamethonium produced muscle pains in the postoperative period, which could be abolished by self-taming and 
precurarisation. But it does not reduce the hyperkalaemic response.

Intubation with non-depolarising muscle relaxants like vecuronium bromide and atracurium besylate where Suxamethonium is contraindicated needs a larger dose and period of waiting for more than 3 minutes. Paton and Waud (1967) have shown that at least $70 \%$ of the receptors at the neuromuscular junction must be occupied before the occurrence of single twitch depression. This is called "neuromuscular margin of safety."2

In an attempt to hasten the onset of paralysis by nondepolarising drugs "priming" technique has been advocated by Foldes FF, 1984.

\section{Classical Action of Non-Depolarising Agents}

Non-depolarising relaxants prevent depolarisation of the endplate, because they are attracted to the acetylcholine recognition sites of the alpha units. After reaching there, they prevent acetylcholine from alighting and causing the ion channel to open. The reaction is a competition between relaxants and acetylcholine and depends upon the relative concentration of the chemicals and their comparative affinities for the receptor.

Vecuronium bromide (Org NC 45) is a monoquaternary analogue of Pancuronium. This agent was synthesised by Savage in 1979 (Churchill Davidson HC), most potent of all the steroid muscle relaxants studied so far. It is a lyophilized cake, and the composition is Vecuronium bromide $4.0 \mathrm{mg}$, citric acid $8.3 \mathrm{mg}$, disodium phosphate $6.5 \mathrm{mg}$, mannitol $24.5 \mathrm{mg}$. The buffer system maintains $\mathrm{pH}$ of 4 in the aqueous solution.

It interacts more selectively with the receptors at the neuromuscular junction, having other cholinergic sites unaffected after full paralysing doses (Marshall et al). The onset times (time from the administration of muscle relaxant to its peak effect) of equivalent doses of Org NC $450.07 \mathrm{mg} / \mathrm{kg}$, tended to be shorter than that of Pancuronium $0.1 \mathrm{mg} / \mathrm{kg}$. Recovery time (25\% to $75 \%$ recovery of control twitch tension) was also shorter for vecuronium (Bencini et al). ${ }^{3}$

With reasonable doses of non-depolarising muscle relaxant, conditions suitable for tracheal intubation cannot be achieved in less than $2-3$ minutes and the onset time required for the development of their maximal effect is $5-6$ minutes. This applies equally to the long and short-acting nondepolarising muscle relaxants like vecuronium bromide and atracurium besylate (Foldes FF). Vecuronium is devoid of the cardiovascular side effects inherent in the use of majority of non-depolarising muscle relaxants. It does not cross the placental barrier in concentrations that significantly affect the new born (Braka et al). Children being significantly more resistant to the neuromuscular blockade to the effects of vecuronium than adolescents (Goudsonzian et al.).

Administration of depolarising drug following nondepolarising drug is dangerous. It increases the resistance towards the blocking effect of the depolarising drug, therefore high doses may cause end plate desensitisation and prolong post-operative apnoea (Kreg et al). Excretion studies have demonstrated that an average of $15 \%-20 \%$ of vecuronium is excreted via the kidneys. Biliary excretion may be the alternative pathway for this drug. Therefore, the drug can be safely used in patients with renal impairment with only minimal increase in duration response (Kerr et al).
Vecuronium bromide is marketed as ampoules. Each ampoule contains vecuronium bromide in a buffered freezedried form with 1 ampoule of water for injection as solvent. The solution should be freshly prepared before use. The powder ampoules can be kept for three years provided stored in dark at a temperature below $25^{\circ} \mathrm{C}$.

The aim of the study is to evaluate the intubating conditions and time required for rapid, smooth tracheal intubation using the "principle of priming" with nondepolarising muscle relaxant vecuronium Bromide.

\section{Objective of the Study}

This study was taken up with the primary objective of evaluating the different priming doses of vecuronium bromide at the time of intubation and the secondary objective of evaluating the intubation conditions.

\section{MATERIALS AND METHODS}

This was a randomised, prospective, double-blinded study that was conducted in patients for abdominal, head and neck surgeries under general anaesthesia in the Department of Anaesthesia, SVRR Govt. General Hospital, Tirupati, AP. For the sake of convenience, it was decided to include 60 subjects in the study with 20 subjects randomised to each of the three study groups. 60 patients of ASA physical status class I and II patients of either sex whose ages ranged from 10 to 60 years and weighed 25 to $70 \mathrm{kgs}$ undergoing elective head and neck, abdominal and ENT surgical procedures were studied after informed duly signed written consent. ${ }^{4}$ They were free from neuromuscular diseases and were not receiving any medication affecting sensitivity to neuromuscular blocking drugs. Patient refusal, pregnancy, significant hepatic, renal and/or metabolic disorder, known allergy to vecuronium and likely to present intubation difficulty were eliminated from the study.

All patients were pre-medicated with butorphanol $1 \mathrm{mg} \mathrm{IM}$ and glycopyrrolate $0.004 \mathrm{mg} / \mathrm{kg}$ intramuscularly 45 minutes prior to induction of anaesthesia. In the operation theatre an intravenous infusion was started and basic parameters like pulse rate, Sp02, blood pressure, ECG and respirations were monitored.

Informed written consent was obtained in the native vernacular language.

The 60 patients were randomly divided into three groups according to computer generated numbers.

\section{Group I}

This group consisting of 20 patients were given preoxygenation with $100 \%$ oxygen for 3 minutes. Induction with Propofol $2 \mathrm{mg} / \mathrm{kg}$ and intubating dose of vecuronium 100 $\mu \mathrm{g} / \mathrm{kg}$ was given intravenously and was ventilated with oxygen and nitrous oxide in 1: 2 ratio with total flow of 6 $\mathrm{L} /$ minute. Intubation was done when jaw was fully relaxed. The time taken for intubation was noted and the intubatory conditions were assessed based on criteria described by Lemon et al.

Intubation was attempted by the same individual in all the patients with reasonable skill and technique.

\section{Group II}

All 20 patients of this group received a priming dose of vecuronium $15 \mu \mathrm{g} / \mathrm{kg} 5$ minutes prior to induction of 
anaesthesia. $100 \%$ oxygen was given during this 5 minutes period and was observed for side effects like unable to open eyes, difficulty in swallowing and difficulty in breathing. Pulse rate and respiratory excursions also watched for during this period. At the end of 5 minutes, Propofol $2 \mathrm{mg} / \mathrm{kg}$ intubating dose of vecuronium $60 \mu \mathrm{g} / \mathrm{kg}$ were given and ventilated with oxygen nitrous oxide in the same ratio as in Group 1.

Intubation was attempted when the jaw was fully relaxed, and the intubating conditions were assessed.

\section{Group III}

In this group consisting of 20 patients, priming dose vecuronium $20 \mu \mathrm{g} / \mathrm{kg}$ was given 5 minutes before the induction. All patients breathed $100 \%$ oxygen during this 5 minutes period. At the end of 5 minutes from the dose of priming, Propofol $2 \mathrm{mg} / \mathrm{kg}$ and intubating dose of vecuronium $80 \mu \mathrm{g} / \mathrm{kg}$ was given intravenously and was ventilated with oxygen and nitrous oxide in the same ratio as in Group I. When the jaw fully relaxed intubation was attempted, the intubation conditions were assessed. Intubating conditions were graded as excellent, satisfactory, fair and poor based on the Lemon et al, 1986.

\section{Intubating Conditions}

(Lemon et al, 1986).

\begin{tabular}{|c|c|c|}
\hline Grading & $\begin{array}{c}\text { Intubatory } \\
\text { Score }\end{array}$ & Conditions \\
\hline Excellent & $-601-$ & $\begin{array}{l}\text { Jaw relaxed, vocal cords open } \\
\text { and no bucking }\end{array}$ \\
\hline Satisfactory & 2 & $\begin{array}{l}\text { Jaw relaxed, slight movement of } \\
\text { cords }\end{array}$ \\
\hline Fair & 1 & $\begin{array}{c}\text { Less than favourable, but } \\
\text { intubation possible, bucking } \\
\text { present } \\
\end{array}$ \\
\hline Poor & 0 & Impossible \\
\hline \multicolumn{3}{|c|}{$\begin{array}{c}\text { All these Groups are Assessed, and the Results are } \\
\text { Tabulated }\end{array}$} \\
\hline
\end{tabular}

\section{Statistical Analysis}

A detailed statistical analysis was carried out in the present study. Based on Rao et al study, continuous measurements were presented as mean \pm standard deviation (SD) and categorical measurements were presented as number (\%). One-way analysis of variance (ANOVA) test was used to measure the time of intubation between the three groups and for comparing intubating conditions among the groups. Significance was assessed at $5 \%$ level of significance. Statistical analysis was performed using PASW Statistics 18.0, SPSS Inc., Chicago, IL, USA. Differences yielding $\mathrm{p}<0.01$ were considered statistically significant.

\section{RESULTS}

Table 1 shows the demographic data. All the groups were statistically comparable with respect to age, sex, weight and ASA physical status. Table 2 shows the comparison of the time of intubation among the three groups. The onset time of intubation was $149 \pm 13$ in Group I, $96 \pm 12$ in Group II and 63 \pm 7.1 in Group III the control group. The primed group with priming interval of 3 mins showed a statistically significant decrease in the onset time of intubation. Intergroup comparison between groups I and II, I and III, and II and III showed $\mathrm{P}<0.01$, which was statistically significant. Table 3 compares the intubating conditions among three groups. Overall excellent, satisfactory and fair intubating conditions were obtained in all patients in the three groups.

\begin{tabular}{|c|c|c|c|c|}
\hline Parameter & Group I & Group II & Group III & P value \\
\hline Age & $38 \pm 10.7$ & $38.1 \pm 9.2$ & $40.3 \pm 10$ & 0.61 \\
\hline Sex (M/F) & $13 / 17$ & $19 / 11$ & $17 / 13$ & 0.138 \\
\hline Weight & $60.5 \pm 8.3$ & $61.2 \pm 7.3$ & $63.5 \pm 10.1$ & 0.41 \\
\hline ASA PS (I/ II) & $21 / 9$ & $19 / 11$ & $20 / 10$ & 0.126 \\
\hline \multicolumn{5}{|c|}{ Table 1. Demographic Data } \\
\hline
\end{tabular}

ASA PS: American Society of Anaesthesiologists Physical Status.

\begin{tabular}{|c|c|c|}
\hline \multirow{2}{*}{ Time of Intubation } & Mean \pm SD & \multirow{2}{*}{$<0.01$} \\
\cline { 2 - 2 } & & \\
\hline Group I & $149 \pm 13$ & \\
\hline Group II & $96 \pm 12$ & \\
\hline Group III & $63 \pm 7.1$ & \\
\cline { 1 - 2 } $\begin{array}{c}\text { Table 2. Comparison of Intubation Time (Time Interval } \\
\text { between Intubating Dose of Vecuronium and } \\
\text { Priming of TOF Stimuli) }\end{array}$ \\
\hline
\end{tabular}

SD: Standard Deviation, TOF: Train-of-Four

\begin{tabular}{|c|c|c|c|c|}
\hline $\begin{array}{c}\text { Intubating } \\
\text { Conditions }\end{array}$ & $\begin{array}{c}\text { Excellent } \\
\text { (E) }\end{array}$ & $\begin{array}{c}\text { Satisfactory } \\
\text { (S) }\end{array}$ & $\begin{array}{c}\text { Fair } \\
\text { (F) }\end{array}$ & \multirow{2}{*}{ P } \\
\hline Group I & $12(60 \%)$ & $2(10 \%)$ & $6(30 \%)$ & \multirow{2}{*}{$>0.05$} \\
\hline Group II & $15(75 \%)$ & $3(15 \%)$ & $2(10 \%)$ & \\
\hline Group III & $17(85 \%)$ & $3(15 \%)$ & ----- & \\
\hline \multicolumn{3}{|l|}{ Table 3. Comparison of Intubating Conditions } \\
\hline
\end{tabular}

All the 3 groups were statistically comparable with respect to age, sex, weight and ASA physical status. Comparison of Intubation time and Intubating conditions among the 3 Groups were studied. In Group I (control) in which patients received a bolus intubating dose of vecuronium, $100 \mu \mathrm{g} / \mathrm{kg}$, the mean intubation time was 149 seconds and adequate intubating conditions were found in $70 \%$ of patients. In Group II where patients received vecuronium $15 \mu \mathrm{g} / \mathrm{kg}$ as priming dose and $60 \mu \mathrm{g} / \mathrm{kg}$ as intubating dose, the mean intubation time was 96 seconds and adequate intubating conditions were found in $80 \%$ of cases. Group III patients who received a priming dose of $20 \mu \mathrm{g} / \mathrm{kg}$ and intubating dose of $80 \mu \mathrm{g} / \mathrm{kg}$ vecuronium, the mean intubation time was 63 seconds and adequate intubating conditions were achieved in $100 \%$ of cases. Intergroup comparison between Groups I and II, I and III and II and III showed $p$ values of $<0.01$ at time of intubation which was statistically significant. Intubation conditions among the three groups showed no statistically significant variation $(p>0.05)$.

\section{DISCUSSION}

Fast onset of action permitting early tracheal intubation is one of the desirable properties of neuromuscular blocking agents. Succinylcholine is currently the drug of choice to facilitate rapid intubation of trachea during anaesthesia, but frequently is associated with some undesirable effects such as muscle fasciculations, post-operative muscle pain, hyperkalaemia, increased intraocular pressure, increased intragastric pressure and malignant hyperthermia. With reasonable doses of non-depolarising muscle relaxant, conditions suitable for tracheal intubation cannot be achieved in less than $2-3$ minutes, and the onset time required for the development of 
their maximal effect is 5 - 6 minutes. This applies equally to the long, medium and the relatively short-acting non-depolarising muscle relaxants such as vecuronium bromide and atracurium besylate. In some conditions various other methods like selftaming, precurarisation intubation with larger doses of nondepolarising drugs are used with certain amount of success.

Foldes and Associates proposed the "priming principle," which appears to accomplish this need. Priming principle consists of $15 \%-20 \%$ of customary intubating doses of nondepolarising relaxant before induction allowing sufficient time for the drug to reach the receptors followed by $50 \%-60 \%$ of the usual intubating dose administered after induction of anaesthesia and 6 - 7 minutes after the priming dose produced satisfactory muscular relaxation for tracheal intubation in 40 90 seconds. A suitable priming dose should allow the patient to maintain adequate ventilation and cause no unpleasant symptoms.

The Rationale of the Divided Dose Technique of Administration of Muscle Relaxant for Facilitation of Rapid Tracheal Intubation is based on the following-

1. The high margin of neuromuscular transmission that allows $70 \%-75 \%$ occupy of the cholinergic receptors without any significant effect of neuromuscular activity.

2. The observation that doses of muscle relaxant that moderately decreased grip strength indicating greater than $70 \%$ receptor occupancy caused no unpleasant symptoms in conscious volunteers, and

3. The onset time of marginally effective doses of muscle relaxant was 5 - 8 minutes.

A small (usually sub-paralysing) dose of non-depolarising neuromuscular blocking drug partially may occupy the postjunctional receptors and/or inhibit pre-synaptic release of acetylcholine (Bowman 1980) allowing more rapid and profound effect of second dose. It was assumed that administration of a second larger dose of muscle relaxant at the time of development of the maximal effect of the "priming" dose rapidly would increase receptor occupancy to $90 \%$ - 92\% level required for neuromuscular block.

\section{Group I}

(Control) consists of 20 patients, who received a bolus dose of $100 \mu \mathrm{g} / \mathrm{kg}$ vecuronium. Intubation was attempted when the jaw was fully relaxed, and the intubating conditions were assessed. The mean intubation time was 149 seconds. This finding correlate with the results of Foldes et al. Schwartz et al claims adequate intubating conditions in all the patients; in our study only $70 \%$ of patients. The reason could be that the patients in Schwartz et al received premedication with pethidine, diazepam and balanced anaesthesia was induced with droperidol, fentanyl and thiopentone which could have influenced the intubatory conditions.

\section{Group II}

Consists of 20 patients, who received a priming dose of 15 $\mu \mathrm{g} / \mathrm{kg}$ and intubating dose of $60 \mu \mathrm{g} / \mathrm{kg}$ of vecuronium. The mean intubation time was 96 seconds and adequate intubating conditions were found in $80 \%$. This slightly differ from the studies of Schwartz et al and Foldes et al, as they observed shorter intubation time ( 69 seconds) and adequate intubating conditions in $100 \%$ of patients. This could be attributed to the obvious reasons mentioned earlier.

\section{Group III}

Consisting of 20 patients received priming dose of $20 \mu \mathrm{g} / \mathrm{kg}$ and intubating dose of $80 \mu \mathrm{g} / \mathrm{kg}$ of vecuronium. The mean intubating time was 63 seconds and adequate intubating conditions were achieved in $100 \%$ of cases. This correlates with Schwartz et al results of 55 seconds and $100 \%$ adequate intubating conditions. But they received intubating dose of $0.06 \mathrm{mg} / \mathrm{kg}$ slightly less compared to our dose of $0.8 \mathrm{mg} / \mathrm{kg}$.

The size of the priming dose or intubating dose had influence on intubation time and no influence on intubation conditions among the above groups. The 20 patients of group III, who received $20 \mu \mathrm{g} / \mathrm{kg}$ vecuronium while awake experienced no discomfort during the 3 - 4 mins that elapsed until the administration of Propofol. Following the administration of $80 \mu \mathrm{g} / \mathrm{kg}$ intubating dose of vecuronium, they arbitrarily were intubated at 60 seconds. Intubation time in this group was small to those observed in group I and II. Intubation conditions were similar in all groups. 5,6

This study demonstrates that intubation time is quicker when a non-depolarising neuromuscular blocking drug is preceded by a small dose of the same or another subparalysing dose of non-depolarising muscle relaxant (Mehta et al). This finding agrees with Nagashima et al, Foldes et al and Gergis et al that when non-depolarising blocking drugs are administered in divided doses the onset of neuromuscular blockade is shorter. This study also demonstrates that there is definite decrease in intubation time and better intubating conditions with increase in the dosage of muscle relaxant.

In Addition to the Facilitation of Rapid Intubation, there are 2 other Advantages to the Divided Dose Method Administration of Vecuronium-

1. Since the sum of the priming and intubating doses is smaller than the conventional intubating dose, the clinical duration of the first dose is reduced by about $25 \%$ which may be desirable in short surgical procedures.

2. The exaggerated reaction of a patient to the priming dose will alert the anaesthesiologist to the presence of hypersensitivity to non-depolarising muscle relaxant.

\section{Limitation of the Study}

Due to short duration of study, convenience sampling technique was followed. Thus, sampling size was also calculated by convenience.

\section{CONCLUSION}

When a non-depolarising neuromuscular blocking drug is preceded by the same or another sub-paralysing dose of nondepolarising muscle relaxant, there is shorter onset of neuromuscular blockade. This method may be used to facilitate rapid endotracheal intubation when succinylcholine is contraindicated.

\section{REFERENCES}

[1] Baumgarten RK, Carter CE, Reynolds WJ, et al. Priming with non-depolarizing relaxants for rapid tracheal intubation: a double-blind evaluation. Canadian Journal of Anaesthesia 1988;35(1):5-11. 


\section{Jemds.com}

[2] Taboada JA, Rupp SM, Miller RD. Refining the priming principle for vecuronium during rapid-sequence induction of anesthesia. Anesthesiology 1986;64(2):243-7.

[3] Culling RD, Middaugh RE, Menk EJ. Rapid tracheal intubation with vecuronium: the timing principle. Journal of Clinical Anesthesia 1989;1(6):422-5.

[4] Moro ET, Módolo NSP. Rapid sequence induction of anesthesia. Rev Bras Anestesiol 2004;54(4):595-606. http://www.scielo.br/scielo.php?script=sci_arttext\&pi d.
Original Research Article

[5] Schwarz S, Ilias W, Lackner F, et al. Rapid tracheal intubation with vecuronium: the priming principle. Anesthesiology 1985;62(4):388-91.

[6] Gerenstein RI, Steinberg D, Martinez-Aguirre E. Priming principle and low dose of vecuronium. J Clin Anesth 1995;7(2):173-5. 